$12.1 ; 13.2$

\title{
Модификация эмиссионной поверхности науглероженного иридиевого полевого эмиттера при адсорбции атомов бария
}

\author{
(ㄱ Д.П. Бернацкий, В.Г. Павлов \\ Физико-технический институт им. А.Ф. Иофффе РАН, Санкт-Петербург, Россия \\ E-mail: bernatskii@ms.ioffe.ru
}

Поступило в Редакцию 30 апреля 2021г.

В окончательной редакции 3 июня 2021 г.

Принято к публикации 4 июня 2021 г.

С помощью полевой электронной микроскопии исследована модификация эмиссионной поверхности науглероженного иридиевого полевого эмиттера при изменении концентрации атомов бария на поверхности в пределах монослойного покрытия. Адсорбция бария при температуре $T=300 \mathrm{~K}$ не приводит к существенным изменениям полевых электронных изображений. При $T=1200 \mathrm{~K}$ на графене на плоскости (100) образуются островки бария. При $T=1500 \mathrm{~K}$ происходит растворение бариевого островка и интеркалирование графена атомами бария. Эмиссионная поверхность увеличивается и становится однородной по эмиссии.

Ключевые слова: полевая электронная эмиссия, углерод, иридий, барий, интеркалирование, полевые эмиттеры.

DOI: 10.21883/PJTF.2021.18.51466.18854

Применение полевых эмиттеров в различных областях науки и техники является важной научной и практической задачей [1-3]. Покрытие металлических полевых электронных эмиттеров углеродом значительно улучшает стабильность их работы [3-5]. На величину и стабильность тока полевой электронной эмиссии сильное влияние оказывает работа выхода поверхности эмиттера. Хорошо известно, что адсорбция на поверхности атомов щелочных и щелочно-земельных металлов снижает работу выхода. В [6] было показано, что при адсорбции атомов цезия на поверхность науглероженного иридиевого полевого эмиттера при температуре $T=300 \mathrm{~K}$ атомы цезия могут находиться не только на поверхности графена, но и под слоем графена в результате процесса интеркалирования. Обе фазы оказывают влияние на работу выхода. Однако цезий, как и другие щелочные металлы, слабо связан с поверхностью металла. Связь осуществляется в основном электростатическими силами: валентный электрон переходит в металл и образующийся ион притягивается к металлу силами зеркального изображения. Атомы цезия можно было легко удалить с поверхности с помощью нагрева либо десорбцией электрическим полем.

До сих пор изучалась полевая электронная эмиссия металлических эмиттеров с пленкой графена только при адсорбции щелочных металлов. При адсорбции двухвалентных щелочно-земельных металлов один из валентных электронов переходит в металл, а другой остается в атоме и обеспечивает более сильную, чем в случае щелочных металлов, связь с поверхностью. Кроме того, в отличие от электростатического отталкивания адсорбированных на поверхности металла или графена атомов щелочных металлов атомы щелочноземельных металлов притягиваются друг к другу и могут образовывать двумерные островки $[7,8]$. Связь в островке дополнительно увеличивает энергию десорбции и стабильность покрытия. Представляет научный и практический интерес изучение влияния адсорбции электроположительных атомов, более сильно связанных с поверхностью, в частности атомов бария, на эмиссионные свойства науглероженного иридиевого полевого эмиттера. В настоящей работе для исследований использовался полевой эмиссионный (электронный и десорбционный) микроскоп [9], в котором для получения увеличенного изображения поверхности ( $10^{5}$ раз) используется проекция поверхности образца эмитируемыми электронами на люминесцентный экран. Для усиления слабых токов с поверхности полевого эмиттера перед люминесцентным экраном расположена сборка из двух микроканальных пластин диаметром $56 \mathrm{~mm}$. В электронном режиме проводилось измерение тока полевой электронной эмиссии и получение графиков Фаулера-Нордгейма для определения работы выхода поверхности и параметров полевого эмиттера. В десорбционном режиме определялись напряженность электрического поля, необходимого для десорбции, и места десорбции.

Образцы полевого эмиттера в виде острия изготавливались из иридиевой проволоки путем электрохимического травления. Затем в высоком вакууме (при давлении $p \sim 5 \cdot 10^{-9}$ Torr) осуществлялся отжиг полученных образцов при температуре $T=2300 \mathrm{~K}$. Во время отжига происходила очистка эмиттера и формирование монокристаллической квазисферической вершины острия с радиусом порядка $500 \mathrm{~nm}$ с выходом на поверхности плоских низкоиндексных граней. Образование монокристаллической вершины эмиттера контролировалось по появлению характерных для иридия полевых электронных изображений. Формирование углеродного покрытия 




Рис. 1. Зависимость работы выхода науглероженного иридиевого полевого эмиттера от степени покрытия барием при $T=300 \mathrm{~K}$.

на эмиттерах проводилось в парах бензола при давлении $\sim 10^{-5}$ Torr и температуре образца $1700 \mathrm{~K}$ [10]. На поверхности иридия атомы углерода, образовавшиеся в результате диссоциации бензола, образуют однослойное графеновое покрытие в области низкоиндексных плоских граней. В переходной области от плоской грани к криволинейной поверхности существует ряд моноатомных ступеней иридия, на которых возможно образование нескольких слоев графена и получение полевого электронного изображения, характерного для ребристого кристалла [11]. Образование графена на поверхности иридиевого полевого эмиттера сопровождается понижением работы выхода до значения $\varphi=4.3 \mathrm{eV}$.

При напылении атомов бария на поверхность иридиевого полевого эмиттера с пленкой графена при температуре эмиттера $T=300 \mathrm{~K}$ проводилась видеорегистрация полевого электронного изображения и вычислялась работа выхода из характеристик Фаулера-Нордгейма [12,13]. Работа выхода поверхности $\varphi$ при увеличении степени покрытия $\Theta$ поверхности барием уменьшалась от значения $\varphi=4.3 \mathrm{eV}$ (науглероженный эмиттер) до $\varphi=2.3 \mathrm{eV}$ (монослойное покрытие барием), проходя через минимум работы выхода $\varphi=2.0 \mathrm{eV}$ при оптимальном покрытии $(\Theta=1)$. Зависимость работы выхода полевого эмиттера от степени покрытия барием поверхности представлена на рис. 1. На рис. 2 приведены полевые электронные изображения поверхности полевого эмиттера. При комнатной температуре изображение практически не зависело от степени покрытия поверхности барием (рис. 2,a). Изменялось только напряжение, необходимое для получения полевой электронной эмиссии.

После нанесения монослойного покрытия бария на поверхность эмиттера производился отжиг эмиттера с регистрацией полевых электронных изображений и вычислением работы выхода поверхности. На рис. 2, $b$ приведено полевое электронное изображение поверхности полевого эмиттера в области грани (100) после отжига при температуре $T=1200 \mathrm{~K}$ в течение $20 \mathrm{~s}$. При этой температуре происходит миграция атомов бария по поверхности и образование островков бария в центральной области грани (100). На плоских образцах иридия (текстурированные ленты с преимущественным выходом грани (111)) с графеном при адсорбции бария в работах $[7,8]$ изучалось интеркалирование барием графена, было дано объяснение образования двумерных островков бария в области температур $1000<T<1500 \mathrm{~K}$. Было сделано предположение о существовании активационного барьера на границе островка для мигрирующих атомов бария. Было показано, что при температуре иридия $T>900 \mathrm{~K}$ идет миграция атомов бария по поверхности и интеркалирование атомами бария графена, а при $T>1600 \mathrm{~K}$ происходит десорбция атомов бария не только с поверхности, но и из интеркалированного состояния. Работа выхода поверхности иридиевого полевого эмиттера после отжига при $T=1200 \mathrm{~K}$ увеличилась от $2.3 \mathrm{eV}$ до значения $3.9 \mathrm{eV}$. Учитывая разницу в энергии десорбции одиночного атома бария на графене $(1.9 \mathrm{eV})$ и энергию десорбции из связанного состояния в островке бария на графене $(3.4 \mathrm{eV})$ [7], следует предположить, что при $T=1200 \mathrm{~K}$ и выше практически нет одиночных адсорбированных на поверхности атомов бария и работа выхода определяется островками бария.

На рис. 2, с приведено полевое электронное изображение поверхности полевого эмиттера в области грани (100) Ir после отжига эмиттера с монослоем бария при температуре $T=1500 \mathrm{~K}$. При этой температуре островки бария на графене не образуются, идет процесс интеркалирования атомами бария графена и происходит десорбция одиночных атомов бария с графена. Работа выхода поверхности по сравнению с работой выхода при $\Theta=0$ уменьшается до значения $\varphi=4.0 \mathrm{eV}$. Эмиссионная поверхность становится однородной и занимает всю площадь графена на грани (100). Увеличение площади эмиссионной поверхности и однородность полевой электронной эмиссии связаны с процессом интеркалирования атомами бария графеновых структур, образовавшихся на поверхности полевого эмиттера после науглероживания.

Судя по неизменности полевых изображений и эмиссионных характеристик, разрушение графенового слоя с десорбцией интеркалированных атомов бария не происходило до температуры $2000 \mathrm{~K}$. Полевая десорбция интеркалированных графеном атомов бария с поверхности эмиттера требовала большей напряженности электрического поля $\left(>10^{10} \mathrm{~V} / \mathrm{m}\right)$, чем в случае щелочных металлов $\left(\sim 5 \cdot 10^{9} \mathrm{~V} / \mathrm{m}\right)$. 


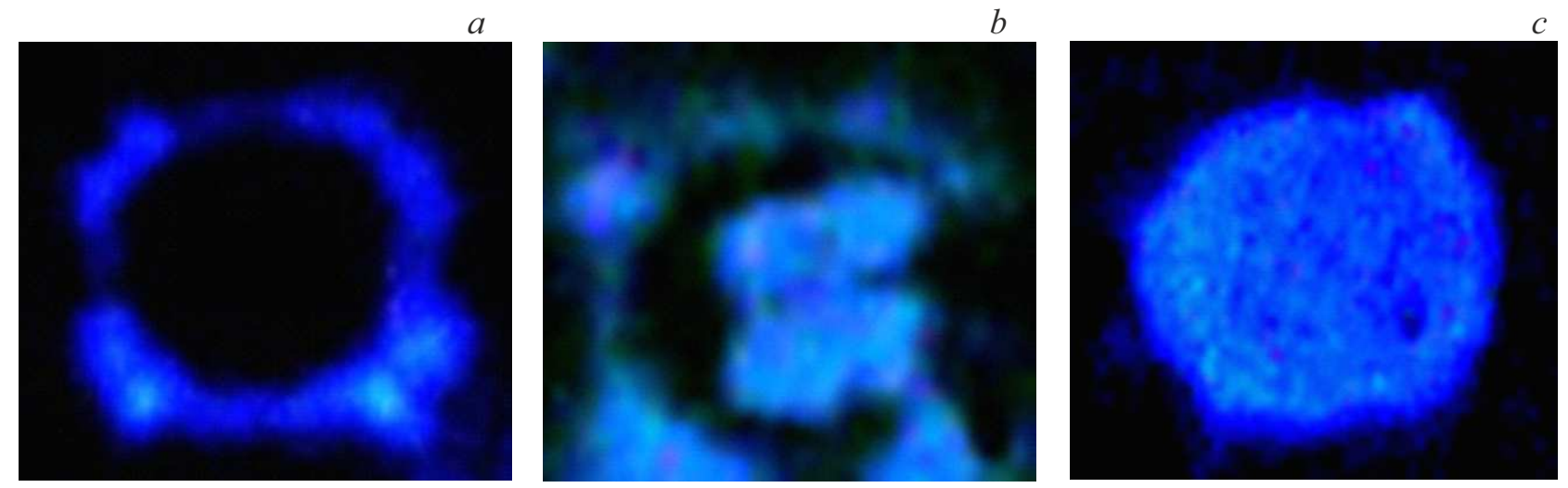

Рис. 2. Полевые электронные изображения поверхности науглероженного иридиевого полевого эмиттера. $a-$ степень покрытия барием $\Theta=0, T=300 \mathrm{~K} ; b-$ образование островка бария, отжиг при $T=1200 \mathrm{~K} ; c$ - интеркалирование графена на грани (100) Ir атомами бария после отжига при $T=1500 \mathrm{~K}$.

Таким образом, в результате исследований показана возможность модификации эмиссионной поверхности науглероженного иридиевого полевого эмиттера при адсорбции атомов бария. В результате модификации происходит понижение работы выхода поверхности эмиттера, увеличение эмиссионной площади и имеет место более однородная эмиссия при образовании графеновых структур на поверхности эмиттера и выполнении условий их интеркалирования атомами бария. Полученное покрытие, улучшающее эмиссионные свойства, более устойчиво по отношению к температурным и полевым нагрузкам по сравнению с покрытиями, полученными с использованием щелочных металлов.

\section{Финансирование работы}

Работа выполнена в рамках государственного задания по теме 0040-2014-0021.

\section{Конфликт интересов}

Авторы заявляют, что у них нет конфликта интересов.

\section{Список литературы}

[1] S. Kumar, G.S. Duesberg, R. Pratap, S. Raghavan, Appl. Phys. Lett., 105, 103107 (2014). DOI: 10.1063/1.4895022

[2] L. Chen, H. Yu, J. Zhong, L. Song, J. Wu, W. Su, Mater. Sci. Eng. B, 220, 44 (2017). DOI: 10.1016/j.mseb.2017.03.007

[3] Е.П. Шешин, Структура поверхности и автоэмиссионные свойства углеродных материалов (Изд-во МФТИ, M., 2001).

[4] Г.Г. Соминский, Т.А. Тумарева, Е.П. Тарадаев, А.А. Рукавицына, М.Е. Гиваргизов, А.Н. Степанова, ЖТФ, 89 (2), 302 (2019). DOI: 10.21833/JTF.2019.02.4786.124-18

[5] F. Giubileo, A. Di Bartolomeo, L. Iemmo, G. Luongo, F. Urban, Appl. Sci., 8, 526 (2018). DOI: $10.3390 / a p p 8040526$

[6] Д.П. Бернацкий, В.Г. Павлов, Письма в ЖТФ, 37 (24), 35 (2011).
[7] Е.В. Рутьков, А.Я. Тонтегоде, ФТТ, 32 (10), 2960 (1990).

[8] Н.Р. Галль, Е.В. Рутьков, Физика поверхности твердых тел. Графен и графит на поверхности твердых тел (Изд-во Политехн. ун-та, СПб., 2013), с. 111.

[9] Д.П. Бернацкий, В.Г. Павлов, Изв. РАН. Сер. физ., 73 (5), 713 (2009).

[10] E.V. Rut'kov, N.R. Gall, in Physics and applications of graphene - experiments, ed. by S. Mikhailov (InTech, 2011), p. 209-292.

[11] Д.П. Бернацкий, В.Г. Павлов, ФТТ, 58 (1), 196 (2016).

[12] R. Haefer, Z. Phys., 116, 604 (1940).

[13] Ненакаливаемые катоды, под ред. М.И. Елинсона (Сов. радио, М., 1974), с. 166-169. 